\title{
Low salt and low calorie diet does not reduce more body fat than same calorie diet: a randomized controlled study
}

\author{
Hye Jin Kang ${ }^{1}$, Dae Won Jun ${ }^{1 *}$, Seung Min Lee ${ }^{2 *}$, Eun Chul Jang ${ }^{3}$ and Yong Kyun \\ $\mathrm{Cho}^{4}$ \\ ${ }^{1}$ Department of Internal Medicine, Hanyang University College of Medicine, Seoul, South Korea \\ ${ }^{2}$ Department of Food and Nutrition, Sungshin Women's University, Seoul, South Korea \\ ${ }^{3}$ Department of Occupational and Environmental Medicine, Soonchunhyang University College of Medicine, Cheonan, South Korea \\ ${ }^{4}$ Department of Internal Medicine, Kangbuk Samsung Hospital, Sungkyunkwan University School of Medicine, Seoul, South Korea \\ "These authors contributed equally to this work
}

Correspondence to: Dae Won Jun, email: noshin@hanyang.ac.kr

Seung Min Lee, email: smlee@sungshin.ac.kr

Keywords: low salt; obesity; diet

Received: July 28, $2017 \quad$ Accepted: November 16, 2017

Published: January 04, 2018

Copyright: Kang et al. This is an open-access article distributed under the terms of the Creative Commons Attribution License 3.0 (CC BY 3.0), which permits unrestricted use, distribution, and reproduction in any medium, provided the original author and source are credited.

\section{ABSTRACT}

Background: Recent several observational studies have reported that high salt intake is associated with obesity. But it is unclear whether salt intake itself induce obesity or low salt diet can reduce body fat mass. We investigated whether a low salt diet can reduce body weight and fat amount.

Matrials and Methods: The randomized, open-label pilot trial was conducted at a single institution. A total of $\mathbf{8 5}$ obese people were enrolled. All participants were served meals three times a day, and provided either a low salt diet or control diet with same calorie. Visceral fat was measured with abdominal computer tomography, while body fat mass and total body water was measured with bio-impedance.

Results: Reductions in body weight $(-6.3 \%$ vs. $-5.0 \%, p=0.05)$ and BMI $(-6.6 \%$ vs. $-5.1 \%, p=0.03$ ) were greater in the low salt group than in the control group. Extracellular water and total body water were significantly reduced in the low salt group compared to the control group. However, changes in body fat mass, visceral fat area, and skeletal muscle mass did not differ between the two groups. Changes in lipid profile, fasting glucose, and HOMA-IR did not differ between the two groups.

Conclusions: A two-month low salt diet was accompanied by reduction of body mass index. However, the observed decrease of body weight was caused by reduction of total body water, not by reduction of body fat mass or visceral fat mass.

\section{INTRODUCTION}

Recently, multiple studies have shown a strong association between a high salt diet and obesity after adjusting total calorie intake $[1,2]$. A study of 86 Swedish men found that high salt intake had a positive relation with body weight and body mass index (BMI), even after correcting for calories [3]. Another study that utilized the results of the Korea National Health and Nutrition Examination Survey (KNHANES) reported a significant association of salt intake with obesity and central obesity even after correcting for total energy intake [4]. The Danish MONICA study, a retrospective cohort study carried out in Denmark, reported an association between body fat mass and sodium consumption [2]. In a cross sectional study with 184 subjects in the UK, waist circumference and body fat mass increased with increased salt intake [5]. Most previous studies have reported that high salt intake is related to obesity, but all were either cohort studies or cross-sectional studies. Due to the limits of observational studies, these studies could not determine if there is a causal relationship between salt intake and obesity. Thus, it is unclear whether obesity is caused directly by salt intake or by bad eating habits accompanied by excessive sodium consumption. Moreover, no possible mechanism between high salt diet 
and obesity was discussed in any of these studies. It is not clear whether weight gain caused by a high salt diet is attributable to an increase in total body water or body fat mass. Two studies have tested if salt intake is related to body fat mass, but both are retrospective, observational studies that did not properly correct for various factors influencing fat mass other than the level of salt intake. On the contrary, no study on the association between a low salt diet and weight loss has been completed. For these reasons, a long-term, randomized, controlled study with a high level of evidence about how low salt intake has an impact on obesity is needed.

The objective of this study is to investigate the impact of low salt diet on body weight and body fat mass, furthermore to identify any adverse effects.

\section{RESULTS}

\section{Basic characteristics}

The characteristics of participants in the control diet and the low salt group are shown in Table 1. The majority were office workers or housewives by occupation. There was no difference between the control group and the low salt group in salty taste acuity prior to dietary intervention. Average levels of salt intake were $4,170 \mathrm{mg}$ /day in the control group and 4,150 mg/day in the low salt group, which was not significantly different between the two groups. Baseline total calorie intake, obesity-related metabolic markers, and level of physical activity did not differ between the two groups.

\section{Effects of low salt diet on weight and body composition}

The percent of body weight reduction $(-6.3 \% \mathrm{vs}$. $-5.0 \%, p=0.05)$ and BMI reduction $(-6.6 \%$ vs. $-5.1 \%, p=$ 0.03 ) were greater in the low salt group than in the control group (Table 2, Figure 1). Total body water, body fat mass, and fat distribution were measured by bio-impedance. The percent of extracellular water change $(-0.1 \mathrm{~kg}$ vs. $-1.5 \mathrm{~kg}$, $p=0.04)$ and total body water change $(-0.4 \mathrm{~kg}$ vs. $-1.8 \mathrm{~kg}$, $p=0.05$ ) were significantly greater in the low salt group compared to the control group. However, no difference in body fat mass loss or skeletal muscle mass variation was found between the two groups (Table 2, Figure 1). The impacts of salt intake on visceral fat were assessed using abdominal CT. The low salt group showed greater reduction in visceral fat area than the control group, but without statistical difference $\left(-20.6 \mathrm{~cm}^{2}\right.$ vs. $\left.-30.4 \mathrm{~cm}^{2}, p=0.08\right)$.

\section{Effects of a low salt diet on metabolic parameters}

Compared to values prior to treatment, ALT, AST, GGT, triglycerides, fasting glucose, and HOMA-IR were significantly decreased in both groups at the second month of dietary intervention (Table 3). There was no difference between the two groups in absolute values of ALT, AST, GGT, triglycerides, fasting glucose, or HOMA-IR at the second month. Systolic and diastolic pressure decreased in both control and low salt group during two months (Table 3). Systolic blood pressure reduction was greater in the low-salt group, but there was no statistically significant difference between the two groups.

\section{Change in salty taste acuity}

Baseline salty taste acuity was the same in both groups at the start of the study. At the second month of dietary intervention, the control group showed no change in salty taste acuity, while the salty taste acuity of the low salt group was decreased.

\section{Compliance with study diets}

There was no difference in the level of total calorie consumption between the control group $(1,479$ kcal) and the low salt group $(1,501 \mathrm{kcal})$ prior to dietary intervention. During the 2-month intervention period, average total calorie consumption did not differ between the control group $(1,314 \mathrm{kcal})$ and the low salt group $(1,287 \mathrm{kcal})(p=0.74)$.

There was no difference in meal consumption between the two groups; participants in the control group consumed an average of $80.0 \%$ of the three meal boxes each day, while those in the low salt group consumed $78.0 \%$. Participants recorded in food diaries any additional snacks consumed other than those provided in meal boxes. The average calories consumed from non-meal box snacks was $243.2 \mathrm{kcal}$ in the control group and $227.9 \mathrm{kcal}$ in the low salt group, which was not statistically different. The amount of sodium consumed from additional snacks was $273.1 \mathrm{mg}$ and $237.1 \mathrm{mg}$ in the control and low salt groups, respectively, representing no statistical differences. Compliance during the dietary intervention period was evaluated using a 3-day food diary and 24hour urine sodium excretion (Table 4). The levels of salt intake identified in the 3-day food diary were $4,170 \mathrm{mg}$ and 4,160 $\mathrm{mg}$ in the control group and the low salt group, respectively, demonstrating no difference between the two groups $(p=0.96)$. However, levels of salt intake after the 2-month dietary intervention were $3,500 \mathrm{mg}$ in the control group and $1,720 \mathrm{mg}$ in the low salt group $(p<0.001)$. When sodium intake was assessed through 24-hour urine collection during the second month of dietary intervention, sodium excretion was significantly lower in the low salt group compared to that in the control group.

\section{DISCUSSION}

A two-month low salt diet decreased body weight, and the percent of body weight reduction was greater 
Table 1: Baseline characteristics of study participants

\begin{tabular}{|c|c|c|c|}
\hline & $\begin{array}{c}\text { Control group } \\
\quad(n=43)\end{array}$ & $\begin{array}{l}\text { Low salt group } \\
\quad(n=41)\end{array}$ & $p$-value \\
\hline Age (year) & $42.3 \pm 7.3$ & $42.5 \pm 7.6$ & 0.881 \\
\hline Height (cm) & $161.0 \pm 6.8$ & $161.4 \pm 8.1$ & 0.823 \\
\hline Body weight (kg) & $73.9 \pm 8.9$ & $74.8 \pm 12.7$ & 0.700 \\
\hline Body mass index $\left(\mathrm{kg} / \mathrm{m}^{2}\right)$ & $28.4 \pm 2.4$ & $28.6 \pm 3.7$ & 0.781 \\
\hline Waist circumference $(\mathrm{cm})$ & $96.9 \pm 6.1$ & $95.8 \pm 7.7$ & 0.467 \\
\hline Total abdominal fat area & $394.7 \pm 83.3$ & $399.0 \pm 112.7$ & 0.845 \\
\hline Visceral fat area & $143.8 \pm 50.7$ & $145.7 \pm 56.9$ & 0.872 \\
\hline Systolic blood pressure $(\mathrm{mmHg})$ & $128.4 \pm 15.7$ & $129.5 \pm 15.1$ & 0.762 \\
\hline Diastolic blood pressure (mmHg) & $76.8 \pm 10.1$ & $74.9 \pm 8.3$ & 0.373 \\
\hline $\operatorname{ALT}(\mathrm{U} / \mathrm{L})$ & $25.2 \pm 25.9$ & $20.4 \pm 10.4$ & 0.278 \\
\hline $\operatorname{AST}(\mathrm{U} / \mathrm{L})$ & $21.8 \pm 10.1$ & $21.8 \pm 6.3$ & 0.979 \\
\hline$\gamma$-GGT (U/L) & $45.9 \pm 83.8$ & $30.6 \pm 30.0$ & 0.280 \\
\hline Fasting glucose (mg/dl) & $86.5 \pm 16.6$ & $82.8 \pm 21.0$ & 0.381 \\
\hline Triglyceride (mg/dl) & $154.2 \pm 88.1$ & $154.0 \pm 114.6$ & 0.993 \\
\hline HDL-cholesterol (mg/dl) & $50.0 \pm 11.0$ & $53.3 \pm 11.9$ & 0.208 \\
\hline Fasting insulin $(\mu \mathrm{IU} / \mathrm{m})$ & $6.4 \pm 3.6$ & $6.7 \pm 4.2$ & 0.789 \\
\hline HOMA-IR & $25.5 \pm 18.5$ & $25.7 \pm 22.7$ & 0.960 \\
\hline Skeletal muscle mass $(\mathrm{kg})$ & $43.2 \pm 7.0$ & $43.8 \pm 9.1$ & 0.142 \\
\hline Body fat mass $(\mathrm{kg})$ & $27.2 \pm 5.8$ & $27.8 \pm 8.0$ & 0.132 \\
\hline Intracellular water $(\ell)$ & $20.8 \pm 3.5$ & $21.3 \pm 4.1$ & 0.288 \\
\hline Extracellular water $(\ell)$ & $12.8 \pm 2.0$ & $13.1 \pm 2.6$ & 0.096 \\
\hline Total body water $(\ell)$ & $33.7 \pm 5.4$ & $34.5 \pm 6.7$ & 0.193 \\
\hline CT-scan Visceral fat area & $143.8 \pm 49.6$ & $146.3 \pm 56.3$ & 0.942 \\
\hline CT-scan Intra-abdominal fat area & $396.9 \pm 84.4$ & $397.1 \pm 111.9$ & 0.137 \\
\hline
\end{tabular}

ALT: Alanine aminotransferase; AST: Aspartate aminotransferase; $\gamma$-GGT: $\gamma$-glutamyl trasnferase; TG: Triglyceride; HDLcholesterol: High density lipoprotein cholesterol; HOMA-IR: Homeostatic model assessment - insulin resistance; CT-scan: Computer tomography scan $\left({ }^{*} p<0.05\right.$ by Student $t$ test between control and low salt group).

Table 2: Comparison of total body weight, body composition in control and low salt group after 2 months

\begin{tabular}{|c|c|c|c|c|c|c|c|c|c|}
\hline & \multicolumn{3}{|c|}{ Control group } & \multicolumn{3}{|c|}{ Low salt group } & \multicolumn{3}{|c|}{ Change rate $(\%)$ compare to baseline } \\
\hline & Baseline & 2 month & ${ }^{*} p$ & Baseline & 2 month & ${ }^{*} p$ & Control & Low salt & ${ }^{* * k} p$ \\
\hline Body weight change (kg) & $74.1 \pm 8.9$ & $70.3 \pm 8.7$ & $<0.001$ & $75.1 \pm 12.7$ & $70.3 \pm 12.6$ & $<0.001$ & $-5.0 \pm 2.9$ & $-6.3 \pm 3.1$ & 0.05 \\
\hline BMI change $\left(\mathrm{kg} / \mathrm{m}^{2}\right)$ & $28.6 \pm 2.5$ & $27.1 \pm 2.5$ & $<0.001$ & $28.6 \pm 3.7$ & $26.7 \pm 3.8$ & $<0.001$ & $-5.1 \pm 3.0$ & $-6.6 \pm 3.1$ & 0.03 \\
\hline Waist circumference $(\mathrm{cm})$ & $97.0 \pm 6.4$ & $89.6 \pm 7.7$ & $<0.001$ & $95.9 \pm 7.6$ & $88.0 \pm 8.7$ & $<0.001$ & $-7.4 \pm 4.7$ & $-7.9 \pm 3.8$ & 0.60 \\
\hline Skeletal muscle mass change $(\mathrm{kg})$ & $43.5 \pm 7.0$ & $43.2 \pm 6.8$ & 0.154 & $43.4 \pm 8.9$ & $42.9 \pm 8.0$ & 0.643 & $0.5 \pm 2.6$ & $0.1 \pm 11.3$ & 0.83 \\
\hline Body fat mass change $(\mathrm{kg})$ & $26.6 \pm 5.5$ & $23.5 \pm 5.1$ & $<0.001$ & $28.1 \pm 8.0$ & $24.5 \pm 8.1$ & $<0.001$ & $-11.0 \pm 7.7$ & $-12.6 \pm 8.7$ & 0.39 \\
\hline Intracellular water change $(\ell)$ & $20.9 \pm 3.5$ & $20.8 \pm 3.5$ & 0.121 & $21.4 \pm 4.1$ & $20.7 \pm 3.9$ & 0.001 & $-0.6 \pm 2.7$ & $-2.0 \pm 4.0$ & 0.07 \\
\hline Extracellular water change $(\ell)$ & $12.8 \pm 2.0$ & $12.8 \pm 1.9$ & 0.597 & $13.0 \pm 2.5$ & $12.7 \pm 2.4$ & 0.006 & $-0.1 \pm 2.9$ & $-1.5 \pm 3.1$ & 0.04 \\
\hline Total body water change $(\ell)$ & $33.9 \pm 5.4$ & $33.7 \pm 5.3$ & 0.217 & $34.2 \pm 6.5$ & $33.7 \pm 6.3$ & 0.001 & $-0.4 \pm 2.7$ & $-1.8 \pm 3.6$ & 0.05 \\
\hline CT-scan Visceral fat area $\left(\mathrm{cm}^{2}\right)$ & $143.8 \pm 50.7$ & $121.1 \pm 40.4$ & 0.872 & $145.7 \pm 56.9$ & $115.7 \pm 43.2$ & 0.573 & $-20.6 \pm 23.2$ & $-30.5 \pm 26.0$ & 0.08 \\
\hline CT-scan Intra-abdominal fat area $\left(\mathrm{cm}^{2}\right)$ & $394.7 \pm 83.3$ & $352.2 \pm 86.7$ & 0.845 & $399.0 \pm 112.7$ & $344.9 \pm 117.2$ & 0.758 & $-44.3 \pm 33.6$ & $-53.4 \pm 46.2$ & 0.32 \\
\hline
\end{tabular}

BMI: body mass index; CT-scan: Computer tomography scan ( ${ }^{*} p<0.05$ by paired $t$ test, ${ }^{* *} p<0.05$ by Student $t$ test). 
Table 3: Comparison of metabolic parameter change in control and low salt group

\begin{tabular}{|c|c|c|c|c|c|c|c|c|c|}
\hline & \multicolumn{3}{|c|}{ Control group } & \multicolumn{3}{|c|}{ Low salt group } & \multicolumn{3}{|c|}{ Mean difference } \\
\hline & Baseline & 2 month & "p & Baseline & 2 month & p & Control & Low salt & ${ }^{* * *} p$ \\
\hline $\operatorname{ALT}(\mathrm{U} / \mathrm{L})$ & $25.5 \pm 25.7$ & $14.5 \pm 11.5$ & $<0.001$ & $19.9 \pm 9.8$ & $11.5 \pm 4.7$ & $<0.001$ & $-11.0 \pm 18.4$ & $-8.5 \pm 8.4$ & 0.425 \\
\hline AST (U/L) & $22.1 \pm 10.2$ & $14.2 \pm 6.5$ & $<0.001$ & $21.3 \pm 5.7$ & $12.8 \pm 2.9$ & $<0.001$ & $-7.9 \pm 7.9$ & $-8.6 \pm 5.4$ & 0.647 \\
\hline$\gamma$-GGT (U/L) & $44.6 \pm 81.9$ & $25.8 \pm 45.5$ & 0.004 & $27.8 \pm 19.8$ & $15.3 \pm 10.2$ & $<0.001$ & $-18.8 \pm 39.9$ & $-12.5 \pm 12.2$ & 0.341 \\
\hline Triglyceride (mg/dl) & $156.3 \pm 86.0$ & $97.5 \pm 52.5$ & $<0.001$ & $159.2 \pm 121.0$ & $84.2 \pm 57.4$ & $<0.001$ & $-58.8 \pm 84.7$ & $-75.0 \pm 96.7$ & 0.422 \\
\hline HDL-cholesterol (mg/dl) & $49.7 \pm 11.3$ & $36.2 \pm 12.2$ & $<0.001$ & $52.8 \pm 12.1$ & $35.6 \pm 7.6$ & $<0.001$ & $-13.5 \pm 7.6$ & $-17.3 \pm 10.0$ & 0.060 \\
\hline Fasting insulin $(\mu \mathrm{IU} / \mathrm{m})$ & $8.36 \pm 6.6$ & $8.25 \pm 7.5$ & 0.822 & $7.21 \pm 4.0$ & $6.20 \pm 3.3$ & 0.102 & $-0.1 \pm 3.0$ & $-1.0 \pm 3.5$ & 0.263 \\
\hline Fasting glucose (mg/dl) & $86.7 \pm 16.1$ & $70.5 \pm 11.8$ & $<0.001$ & $82.7 \pm 20.9$ & $68.4 \pm 12.5$ & $<0.001$ & $-16.2 \pm 16.2$ & $-14.4 \pm 17.9$ & 0.622 \\
\hline HOMA-IR & $33.4 \pm 28.2$ & $26.2 \pm 27.2$ & 0.004 & $28.3 \pm 23.3$ & $19.6 \pm 12.8$ & 0.012 & $-6.8 \pm 12.7$ & $-8.7 \pm 19.0$ & 0.634 \\
\hline
\end{tabular}

BMI: body mass index; CT-scan: Computer tomography scan; HU: Hounsfield Unit; ALT; Alanine aminotransferase; AST; Aspartate aminotransferase; $\gamma$-GGT; $\gamma$-glutamyl transferase; HDL-cholesterol: High density lipoprotein cholesterol; HOMA-IR: Homeostatic model assessment - insulin resistance ( ${ }^{*} p$ $<0.05$ by paired $t$ test, ${ }^{* *} p<0.05$ by Student $t$ test).

than that in the control diet group. The decrease in body weight and BMI were caused by reduction in fluid retention, not by reducing body fat mass. To the best of our knowledge, this is the first randomized controlled study testing whether salt restriction decreases body weight or body fat mass.

To date, 17 studies on the relationship between salt intake and obesity have been published, including two cohort studies, [2, 6] 14 cross sectional studies, [1, $4,5,7-17]$ and one case-control study [18]. Although most previous studies have suggested an association between salt intake and obesity, no studies have clearly demonstrated an association between salt intake and fat mass. However, it is still unclear whether salt intake can increase body fat mass or trigger obesity.

Two previous studies have investigated the relationship between salt intake and fat mass $[2,5]$. In the Danish MONICA study, a retrospective cohort study carried out in Denmark, 10-year follow-up of 215 subjects showed that body fat mass increased with an increase in sodium consumption, while free fat mass decreased [2]. The Danish MONICA study also analyzed the correlation between salt intake and body fat mass over 10 years. However, the amount of salt intake was evaluated only once at baseline, and there was no follow up survey regarding changing diet behavior after that. In addition, only 215 of 600 participants (35.8\%) could be followed up. More critically, there was no adjustment of energy intake or soft drink intake. A second study was performed in the UK [5]. In a cross-sectional study of 184 subjects, waist circumference and body fat mass increased with increased salt intake, which was measured through 24-hour urinary sodium excretion, while lean body mass decreased. In the UK study, the 24-hour urinary sodium excretion and anthropometric data were not recorded simultaneously and were tested at different points. Moreover, body fat mass and lean body mass were not directly measured through bio-impedance or dual energy X-ray absorptiometry. Body fat mass was calculated using a double-labeled water method formula. Above all, no causal relationship was found since both studies were observational in design. This study is the first randomized controlled trial examining the effects of a low salt diet on body weight and body fat mass using a controlled diet for 2 months.

Other unsolved issue regarding low salt diet is concern over potential adverse effects that have been suggested by some studies [19, 20]. There are some concerns about deteriorating metabolic parameters due to low salt intake. Several studies have reported that low salt diet can increase insulin resistance and levels of total cholesterol, low density lipoprotein cholesterol, and triglycerides $[8,18]$. However, none of these studies were carried out for longer than two weeks, and some studies were performed using an extremely low salt diet $(<1 \mathrm{~g}$ sodium per day) with a small number of subjects. The influence of low sodium diet on insulin resistance and dyslipidemia is unclear and has shown variable results [21, 22]. A total of 25 studies related to salt intake and insulin resistance have been published by 2015 and have reported different results [23]. Nine of these studies reported that insulin resistance would increase, while seven reported that it would decrease; other studies concluded that no significant differences were observed. Studies that reported negative effects of restricted salt intake on insulin resistance have suggested that restrictions in sodium consumption decrease fluid retention in the body; to compensate for this loss, there are increases in the amounts of epinephrine, renin, and angiotensin, which lead to insulin resistance because these hormones restrict insulin function [18]. However, most studies performed with extremely low salt diets ( $<1$ g sodium per day) have been conducted over a very short period ( $<2$ weeks). While these studies, which provided frozen meal as an intervention, show a clearer causal relationship than would a cross sectional study, it is difficult to conclude that low salt intake has a long-term effect because the intervention period is too short [24, 25]. Our study did not find a significant effect on insulin resistance and lipid metabolism from consuming a low salt diet of 2 grams of sodium daily for 2 months. 
Table 4: Estimated sodium intake according to survey method

\begin{tabular}{lcccccc}
\hline & \multicolumn{2}{c}{ Control diet (5 gram/day) } & \multicolumn{3}{c}{ Low salt diet (2 gam/day) } \\
\cline { 2 - 6 } & Baseline & 2 month & $\boldsymbol{p}^{*}$ & Baseline & 2 month & $\boldsymbol{p}^{*}$ \\
\hline Total food intake $(\mathrm{g})$ & $1488.1 \pm 604.2$ & $1314.9 \pm 362.3$ & 0.097 & $1510.6 \pm 571$ & $1289.2 \pm 364$ & 0.021 \\
Total energy intake (kcal) & $1971.6 \pm 506.8$ & $1445.5 \pm 336.2$ & $<0.001$ & $1986.6 \pm 690$ & $1325.4 \pm 219$ & $<0.001$ \\
Na intake, 3-day diary (g/day) & $4168.9 \pm 1885.0$ & $3508.4 \pm 876.2$ & 0.220 & $4150.1 \pm 1734.3$ & $1725.9 \pm 502.1$ & $<0.001$ \\
24-HU Na excretion (mEq/day) & $172.5 \pm 64.5$ & $152.4 \pm 67.6$ & 0.056 & $186.9 \pm 78.0$ & $123.4 \pm 49.6$ & 0.001 \\
\hline
\end{tabular}

Na: sodium; 24-HU Na excretion: 24-hours urine sodium excretion ( ${ }^{*} p<0.05$ by Student $t$ test between control and low salt group).

There were some limitations in this study. First, while this study was designed as a randomized controlled trial, double-blinding was not possible due to the nature of the low salt diets that were provided. However, the primary endpoint is body weight while the secondary endpoints are body composition, drawn from bioelectric impedance, and biochemical markers. Objective parameters were used as the primary or secondary endpoints. Secondly, while the three-day diet diary and the 24-hour urinary sodium excretion were evaluated to make sure the amount of sodium consumption, it still may not perfect to reflect the actual amount of salt intake. Thirdly, although this is the longest clinical trial testing a low salt diet, a two-month time period may not be sufficient to fully assess metabolic changes and obesity-related parameters. Despite the absence of statistical significance, a significant decrease in body fat mass and visceral fat amount was notable. Intervention study of a longer period would be required to determine the causal relationships between salt intake and fat amounts.

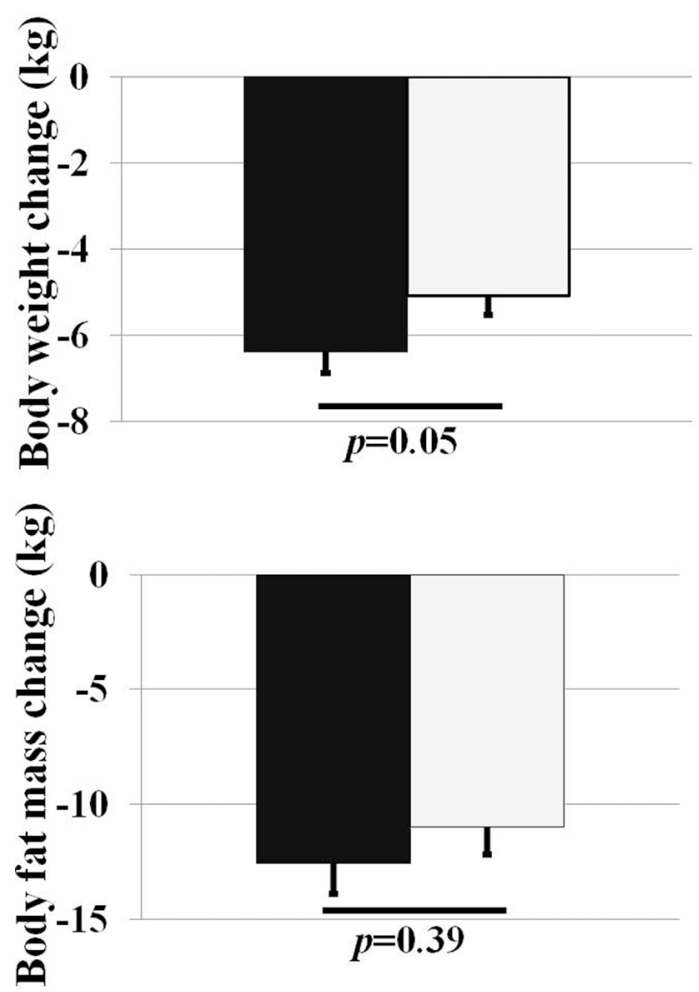

This study demonstrated that BMI and body weight were decreased after a two-month low salt diet program, without significantly adverse effects. However, a low salt diet did not reduce body fat mass or visceral fat area. A twomonth low salt diet was accompanied by reduction of body mass index which was caused by reduction of total body water, not by reduction of body fat mass or visceral fat mass.

\section{MATERIALS AND METHODS}

\section{Design}

This study was a randomized, open label, parallel, pilot trial designed to examine the efficacy of a low salt diet versus control diet for two months. The study was approved by the institutional review board of Hanyang University Hosptial. This study was registered with the Clinical Research Information Service of the Korea Centers for Disease Control and Prevention prior to the

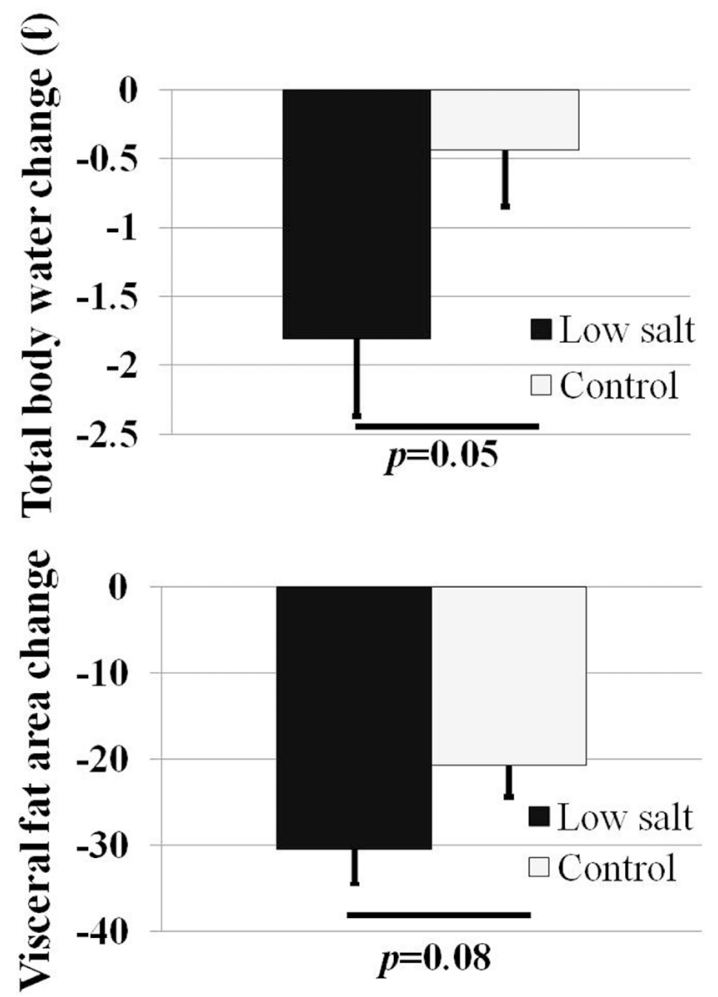

Figure 1: Comparison of total body weight, body composition in low salt and control group after 2 months ( $^{*} p<0.05$ by Student $t$ test between control and low salt group). 
commencement of research (KCT0001084, https://cris. nih.go.kr).

\section{Participants}

Subjects were adults aged 19 to 70 years, all of whom participated voluntarily. This study was conducted at a single institution, Hanyang University Medical Center. The study populations for this study were white-collar workers from a single center and housewives, and data was stratified by sex and BMI. All participants were measured for height and weight and were eligible for the study if they were "obese." The definition of obesity used in Asian countries is different from that used in Western countries. In this study, participants with a body mass index (BMI) of $25 \mathrm{~kg} / \mathrm{m}^{2}$ or more were considered "obese" [26, 27]. All participants provided written informed consent.

Exclusion criteria was such as following. Participants who were newly diagnosed with hypertension, and dyslipidemia in the last six months. Subjects who diagnosed with diabetes mellitus-diabetes mellitus was defined as fasting glucose $\geq 126 \mathrm{mg} / \mathrm{dL}(7.0 \mathrm{mmol} / \mathrm{L})$ or hemoglobin $\mathrm{A} 1 \mathrm{C} \geq 6.5 \%(48 \mathrm{mmol} / \mathrm{mol})$ or those who took oral hypoglycemic agents. Those who take diuretics included thiazides. Those who receive consultation on diet and nutrition in the last six months. Those diagnosed with a malignancy in the previous year. Those who received stomach surgery. Those who underwent thyroidectomy in the last three years, those who regularly visit the hospital more than four times a year and take drugs due to liver, heart, or kidney disease. Men consuming $210 \mathrm{~g}$ of alcohol per week or women consuming $140 \mathrm{~g}$ of alcohol per week; $[28,29]$ and those working night shifts were excluded.

\section{Randomization and allocation}

Subjects were randomly allocated to either the low salt or control group in a 1:1 ratio by computer. We used stratified randomization method according to sex and BMI. Because the taste of food in the low salt diet was flat, participants easily noticed it. Thus, blinding and allocation concealment were not maintained. This study was performed as an open label study.

\section{Follow-up}

A total of 85 subjects were enrolled this study and followed up from April 2014 to May 2014 (Figure 2). One participant withdrew consent during the screening process, and a total of 84 subjects were randomly assigned to two groups: 41 in the low salt group and 43 in the control group. For two months when a meal box was offered three meals a day, three participants were eliminated from the control group: one participant became unexpectedly pregnant and two withdrew consent at the 3rd or 4th week of diet intervention due to 'skimpy meals' based on calorie restriction. Participants were asked to write a food diary every day about the meals provided, and nutritionists reviewed these diaries every week. Those who continued to consume more than $500 \mathrm{kcal}$ in addition to the meals provided or who ate less than $60 \%$ of the meal provided were also eliminated from the study. Sample size was calculated with sample size equation. We used the weight loss values using previous study that assessed weight loss in patients for low salt diet. For a significance level of $\alpha=0.05$, a statistical power of $80 \%$, and a substantial difference in weight loss of $1.78 \mathrm{~kg}$ (experimental arm; $-4.42 \mathrm{~kg}$ vs. control arm; $-2.64 \mathrm{~kg}$ ). Drop-out rate estimated $10 \%$. Final target population was decided as 90 subjects (KCT0001084, https://cris.nih.go.kr).

\section{Dietary intervention}

All participants were served meals three times a day, five days a week from Monday through Friday for two months. Lunch and dinner were provided to each participant, and breakfast was included in a meal box with dinner. During the weekend, the kinds and amount of foods consumed were recorded using a food diary. Lowcalorie meals (an average $1600 \mathrm{kcal}$ based on $25 \mathrm{kcal}$ of body weight per day) were provided to all participants in order to promote weight loss [30]. The calorie and nutrient content of each meal were composed according to criteria recommended by the Dietary Reference Intakes of Koreans (fat $15-20 \%$, protein $20 \%$, and carbohydrate $60-65 \%$ ) [31]. The same energy ratio was supplied to meals for both the low salt group and the control group.

The low salt group was served meals containing 2.0 gram of sodium per day, which is the World Health Organization (WHO)-recommended daily sodium intake, while the control group was served meals containing 5.0 gram of sodium per day [32]. The control meals were based on results from the 2009-2012 Korea National Health and Nutrition Examination Survey (KNHANES), which reported average sodium intakes of 4.5 and 6-6.5 gram per day for women and men, respectively. Among all participants, the average age was 42 years, and women accounted for $77 \%$. The sex ratio, age, and calories supplied were corrected to set 5 gram of sodium for control diet, and the density of sodium ingested is similar to that of real life.

\section{Outcomes}

The primary endpoint was change in percent body mass index compared to baseline. The secondary endpoints were percent of body weight reduction, fat amount, skeletal muscle mass, visceral fat area, and total body water compared to baseline.

\section{Measurement of clinical parameters}

Weight and height were measured using an automatic extensometer. Quality control of the automatic 
extensometer was performed every six months. Waist circumference was measured by placing a tape measure around waist $2 \mathrm{~cm}$ above the highest point of the iliac crests while exhaling, [33] The waist was measured three times and recorded to the 0.1 centimeter without including the thickness of clothing.

Blood collection for biochemical markers was performed after 8-hour fasting. Lipid profile and biochemical markers including triglyceride (TG), high density cholesterol (HDL), serum glucose, insulin, alanine aminotransferase (ALT), aspartate aminotransferase (AST), and $\gamma$-glutamyl transferase $(\gamma$-GGT) levels were measured using an autoanalyzer (Olympus $\mathrm{GmbH}$, Hamburg, Germany). Insulin resistance was calculated by the following formula: HOMA-IR $=$ fasting insulin $(\mu \mathrm{U} / \mathrm{mL}) \times$ fasting plasma glucose (mmol/1)/22.5 [34]. Quality control of biochemical examinations was conducted once a year following the guidelines for external quality control of the Korean Association of Quality Assurance for Clinical Pathology.

The measurement of body composition was conducted using bio-impedance (INBODY 520 Body Composition Analysis). The parameters measured were body composition (body water, protein, minerals, and body fat), skeletal muscle-fat (weight, skeletal muscle mass, and body fat mass), obesity (BMI, body fat ratio, and abdominal fat ratio), and body balance (right arm, left arm, torso, right leg, and left leg). Visceral fat was analyzed using abdominal computer tomography(CT) scan, and the abdominal CT scan used in this study was multi-detector computer tomography with more than 16 slices [35]. Attenuation correction was performed on a daily basis. Abdominal CT scans were performed using a low-dose technique that minimizes radiation exposure (120 kVp, 50-75 mAs), and the slice thickness was $5 \mathrm{~mm}$.

\section{Lifestyle surveys}

Intensity, times, and duration of exercise were evaluated to survey daily life habits using a standard questionnaire used by the KNHANES [36]. Intensity of exercise defined as follows. Severe physical activity defined such as running (jogging), mountain climbing, fast bike riding, fast swimming, soccer, basketball, skipping rope, squash, playing singles tennis, and carrying heavy objects. Moderate physical activity defined such as slow swimming, playing doubles tennis, volleyball, badminton, table tennis, carrying light objects, and walking. Smoking, smoking days, smoking amount, drinking days, drinking amount, dietary supplement intake, and the kinds of dietary supplements were surveyed using a questionnaire used by the KNHANES.

A salty taste acuity test was completed using a computer program for salty taste assessment developed by the Department of Food and Drug Safety [37]. This method was designed to determine the favorite taste of the participant by providing water of five different salinity levels (bland, slightly bland, moderate, slightly salty, and salty). Participants who choose higher salinity water more strongly prefer a salty taste than those who choose lower salinity water.

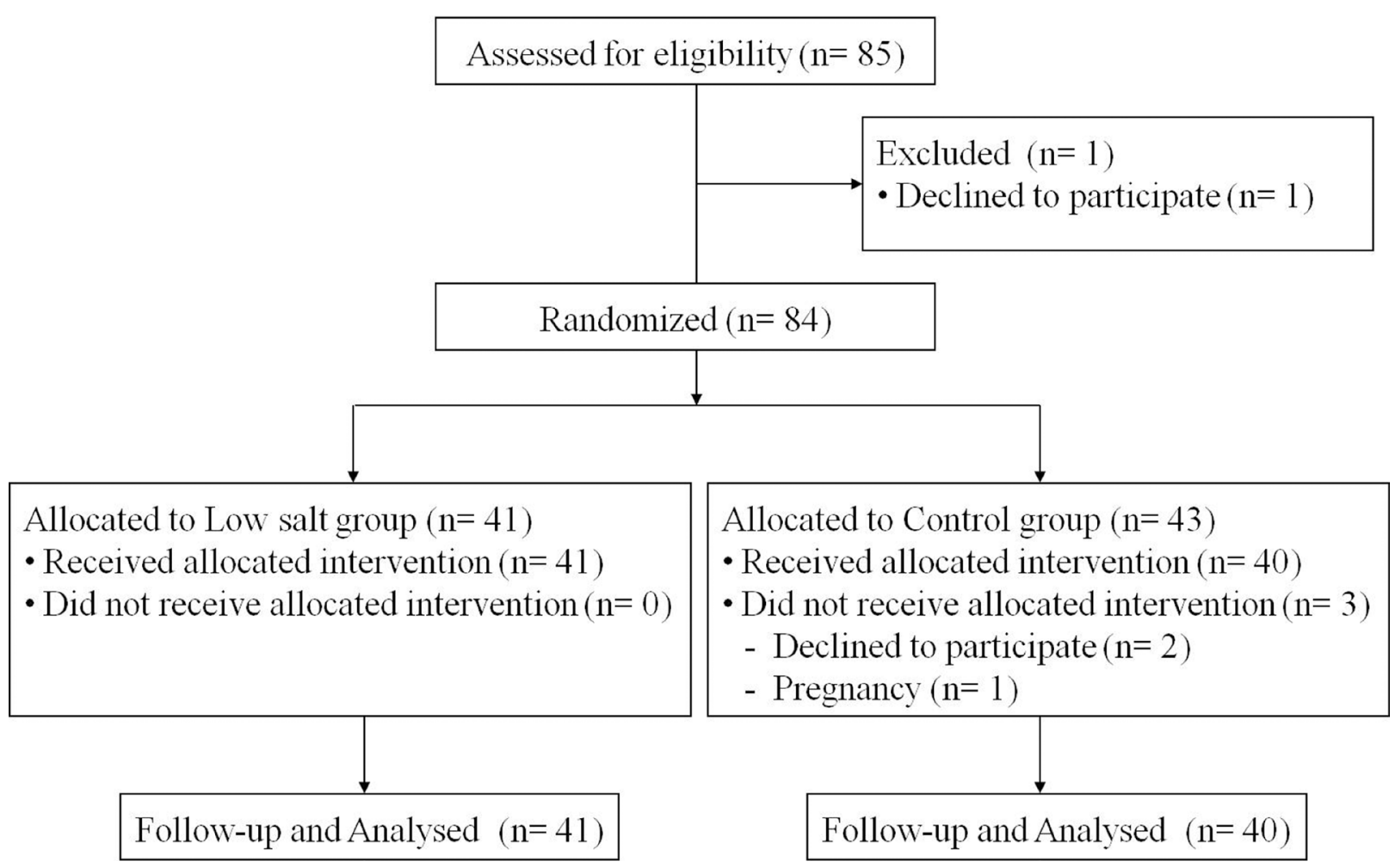

Figure 2: Consort flow chat of randomized controlled study of low salt and control diet. 


\section{Assessment of compliance}

Compliance of subjects was assessed by multifaceted approach. At first, we checked diet compliance with daily food diary during two months. All participant recorded food diary. Participants check intake rate of served meals as well as additional intake of snack during the weekday. Participants recoded the amount of rice and side dishes consumed every day in their served meal during the dietary intervention. Consumption of side dish and rice were scored as follows: 1 point if no side dishes or rice were consumed, 2 points if $25 \%$ of meals included side dishes or rice, 3 points if $50 \%, 4$ points if $75 \%$, and 5 points if all meals contained side dish and rice food. And during the weekend, the kinds and amount of foods consumed were recorded using semi-quantitative method. Nutritionists reviewed it, and also educated suggesting recipe during weekend. Second, three day food diary was investigated at the beginning and end of intervention. Food consumption of noncontinuous three days (including one day of the weekend) were recorded prior to and post dietary intervention. The three-day food diary was used as material according to the CAN-Pro4.0 (Computer Aided Nutritional analysis program) developed by the Korean Nutrition Society. Two skilled nutritionists taught both the low salt group and the control group how to write a food diary using sample food models. A food diary was written by recalling food consumption during the past 24 hours. Third, 24-hour urine collection was performed at the beginning and end of intervention to assess consumption of salt intake $[38,39]$. For the 24-hour urine test, urine from the second urination on the previous morning to the first urination on the following day was collected in an embalmed container. After measuring the gross volume of urine, urine creatinine concentration was determined to verify if an appropriate amount of urine was collected. Urine with creatinine level below $600 \mathrm{mg}$ or over 3,200 mg was excluded.

Participant compliance was $80 \%$ on average, and those with compliance below $60 \%$ were considered withdrawn. There were two non-compliance participants in our study who withdrew consent on the account of insufficient calories intakes, and the change in the result is insignificant.

\section{Statistical analysis}

We included all subjects from the intent-to-treat population, defined as all randomly assigned participants who received meal. Student's $t$-test and Chi-square test were carried out to analyze salt intake-related indicators of body weight, BMI, body fat mass, and biochemical indicators. Paired $t$-test was also used to analyze indicators of body weight, BMI, body fat mass, and biochemical indicators. The statistics program used in this study was SPSS version 21 (IBM SPSS Inc., Chicago, IL, USA).

\section{Author contributions}

Dae Won Jun and Seung Min Lee contributed to the study design and grant; Eun Chul Jang and Yong Kyun Cho collected and analyzed the data and contributed to the design of the study; Hye Jin Kang wrote the manuscript.

\section{ACKNOWLEDGMENTS AND FUNDING}

This work was supported by a grant (14162MFDS134) from the Ministry of Food and Drug Safety in 2014.

\section{CONFLICTS OF INTEREST}

The authors declare no conflicts of interest.

\section{REFERENCES}

1. Song HJ, Cho YG, Lee HJ. Dietary sodium intake and prevalence of overweight in adults. Metabolism. 2013; 62:703-8. https://doi.org/10.1016/j.metabol.2012.11.009.

2. Larsen SC, Angquist L, Sorensen TI, Heitmann BL. 24h urinary sodium excretion and subsequent change in weight, waist circumference and body composition. PLoS One. 2013; 8:e69689. https://doi.org/10.1371/journal. pone. 0069689 .

3. Hulthen L, Aurell M, Klingberg S, Hallenberg E, Lorentzon M, Ohlsson C. Salt intake in young Swedish men. Public Health Nutr. 2010; 13:601-5. https://doi.org/10.1017/ S1368980009991431.

4. Yoon YS, Oh SW. Sodium density and obesity; the Korea National Health and Nutrition Examination Survey 2007-2010. Eur J Clin Nutr. 2013; 67:141-6. https://doi. org/10.1038/ejen.2012.204.

5. Ma Y, He FJ, MacGregor GA. High salt intake:independent risk factor for obesity? Hypertension. 2015; 66:843-9. https://doi.org/10.1161/HYPERTENSIONAHA.115.05948.

6. Mills KT, Chen J, Yang W, Appel LJ, Kusek JW, Alper A, Delafontaine P, Keane MG, Mohler E, Ojo A, Rahman M, Ricardo AC, Soliman EZ, et al. Sodium Excretion and the Risk of Cardiovascular Disease in Patients With Chronic Kidney Disease. JAMA. 2016; 315:2200-10. https://doi. org/10.1001/jama.2016.4447.

7. Sacks FM, Svetkey LP, Vollmer WM, Appel LJ, Bray GA, Harsha D, Obarzanek E, Conlin PR, Miller ER 3rd, SimonsMorton DG, Karanja N, Lin PH, et al, Group DA-SCR. Effects on blood pressure of reduced dietary sodium and the Dietary Approaches to Stop Hypertension (DASH) diet. DASHSodium Collaborative Research Group. N Engl J Med. 2001; 344:3-10. https://doi.org/10.1056/NEJM200101043440101.

8. Hoffmann IS, Cubeddu LX. Salt and the metabolic syndrome. Nutr Metab Cardiovasc Dis. 2009; 19:123-8. https://doi.org/10.1016/j.numecd.2008.02.011. 
9. Grimes CA, Riddell LJ, Campbell KJ, Nowson CA. Dietary salt intake, sugar-sweetened beverage consumption, and obesity risk. Pediatrics. 2013; 131:14-21. https://doi. org/10.1542/peds.2012-1628.

10. Thuesen BH, Toft U, Buhelt LP, Linneberg A, Friedrich N, Nauck M, Wallaschofski H, Jorgensen T. Estimated daily salt intake in relation to blood pressure and blood lipids: the role of obesity. Eur J Prev Cardiol. 2015; 22:1567-74. https://doi.org/10.1177/2047487314553201.

11. Zhou X, Yuan F, Ji WJ, Guo ZZ, Zhang L, Lu RY, Liu X, Liu HM, Zhang WC, Jiang TM, Zhang Z, Li YM. Highsalt intake induced visceral adipose tissue hypoxia and its association with circulating monocyte subsets in humans. Obesity (Silver Spring). 2014; 22:1470-6. https://doi. org/10.1002/oby.20716.

12. Zhu H, Pollock NK, Kotak I, Gutin B, Wang X, Bhagatwala J, Parikh S, Harshfield GA, Dong Y. Dietary sodium, adiposity, and inflammation in healthy adolescents. Pediatrics. 2014; 133:e635-42. https://doi.org/10.1542/ peds.2013-1794.

13. Mozaffarian D. Dietary and Policy Priorities for Cardiovascular Disease, Diabetes, and Obesity: A Comprehensive Review. Circulation. 2016; 133:187-225. https://doi.org/10.1161/CIRCULATIONAHA.115.018585.

14. Deglaire A, Mejean C, Castetbon K, Kesse-Guyot E, Hercberg S, Schlich P. Associations between weight status and liking scores for sweet, salt and fat according to the gender in adults (The Nutrinet-Sante study). Eur J Clin Nutr. 2015; 69:40-6. https://doi.org/10.1038/ejen.2014.139.

15. Navia B, Aparicio A, Perea JM, Perez-Farinos N, VillarVillalba C, Labrado E, Ortega RM. Sodium intake may promote weight gain; results of the FANPE study in a representative sample of the adult Spanish population. Nutr Hosp. 2014; 29:1283-9. https://doi.org/10.3305/ nh.2014.29.6.7361.

16. Campbell N, Correa-Rotter R, Neal B, Cappuccio FP. New evidence relating to the health impact of reducing salt intake. Nutr Metab Cardiovasc Dis. 2011; 21:617-9. https:// doi.org/10.1016/j.numecd.2011.08.001.

17. Kumanyika SK, Cook NR, Cutler JA, Belden L, Brewer A, Cohen JD, Hebert PR, Lasser VI, Raines J, Raczynski J, Shepek L, Diller L, Whelton PK, et al. Sodium reduction for hypertension prevention in overweight adults: further results from the Trials of Hypertension Prevention Phase II. J Hum Hypertens. 2005; 19:33-45. https://doi.org/10.1038/ sj.jhh.1001774.

18. Nakandakare ER, Charf AM, Santos FC, Nunes VS, Ortega K, Lottenberg AM, Mion D Jr, Nakano T, Nakajima K, D’Amico EA, Catanozi S, Passarelli M, Quintão EC. Dietary salt restriction increases plasma lipoprotein and inflammatory marker concentrations in hypertensive patients. Atherosclerosis. 2008; 200:410-6. https://doi. org/10.1016/j.atherosclerosis.2007.12.034.

19. Garg R, Williams GH, Hurwitz S, Brown NJ, Hopkins PN, Adler GK. Low-salt diet increases insulin resistance in healthy subjects. Metabolism. 2011; 60:965-8. https://doi. org/10.1016/j.metabol.2010.09.005.

20. Townsend RR, Kapoor S, McFadden CB. Salt intake and insulin sensitivity in healthy human volunteers. Clin Sci (Lond). 2007; 113:141-8. https://doi.org/10.1042/ CS20060361.

21. Graudal NA, Hubeck-Graudal T, Jurgens G. Effects of low sodium diet versus high sodium diet on blood pressure, renin, aldosterone, catecholamines, cholesterol, and triglyceride. Cochrane Database Syst Rev. 2011: CD004022. https://doi.org/10.1002/14651858.CD004022.pub3.

22. Campbell NR, Cappuccio FP, Tobe SW. Unnecessary controversy regarding dietary sodium: a lot about a little. Can J Cardiol. 2011; 27:404-6. https://doi.org/10.1016/j. cjca.2011.05.003.

23. Oh H, Lee HY, Jun DW, Lee SM. Low Salt Diet and Insulin Resistance. Clin Nutr Res. 2016; 5:1-6. https://doi. org/10.7762/cnr.2016.5.1.1.

24. Geleijnse JM, Witteman JC, Bak AA, den Breeijen JH, Grobbee DE. Long-term moderate sodium restriction does not adversely affect the serum HDL/total cholesterol ratio. J Hum Hypertens. 1995; 9:975-9.

25. Krikken JA, Dallinga-Thie GM, Navis G, Dullaart RP. Short term dietary sodium restriction decreases HDL cholesterol, apolipoprotein A-I and high molecular weight adiponectin in healthy young men:relationships with renal hemodynamics and RAAS activation. Nutr Metab Cardiovasc Dis. 2012; 22:35-41. https://doi.org/10.1016/j.numecd.2010.03.010.

26. WHO Expert Consultation. Appropriate body-mass index for Asian populations and its implications for policy and intervention strategies. Lancet. 2004; 363:157-63. https:// doi.org/10.1016/S0140-6736(03)15268-3.

27. WHO. Obesity: preventing and managing the global epidemic. Report of a WHO consultation. World Health Organ Tech Rep Ser. 2000; 894:i-xii, 1-253.

28. Traversy G, Chaput JP. Alcohol Consumption and Obesity: An Update. Curr Obes Rep. 2015; 4:122-30. https://doi. org/10.1007/s13679-014-0129-4.

29. Yeomans MR. Alcohol, appetite and energy balance: is alcohol intake a risk factor for obesity? Physiol Behav. 2010; 100:82-9. https://doi.org/10.1016/j. physbeh.2010.01.012.

30. Apfelbaum M, Vague P, Ziegler O, Hanotin C, Thomas F, Leutenegger E. Long-term maintenance of weight loss after a very-low-calorie diet: a randomized blinded trial of the efficacy and tolerability of sibutramine. Am J Med. 1999; 106:179-84.

31. Paik HY. Dietary Reference Intakes for Koreans (KDRIs). Asia Pac J Clin Nutr. 2008; 17:416-9.

32. World Health Organization. (2012). Guideline: Sodium Intake for Adults and Children. Geneva. http://www.who.int/nutrition/ publications/guidelines/sodium_intake_printversion.pdf.

33. Nishida C, Ko GT, Kumanyika S. Body fat distribution and noncommunicable diseases in populations: overview of the 
2008 WHO Expert Consultation on Waist Circumference and Waist-Hip Ratio. Eur J Clin Nutr. 2010; 64:2-5. https:// doi.org/10.1038/ejen.2009.139.

34. Matthews DR, Hosker JP, Rudenski AS, Naylor BA, Treacher DF, Turner RC. Homeostasis model assessment: insulin resistance and beta-cell function from fasting plasma glucose and insulin concentrations in man. Diabetologia. 1985; 28 412-9.

35. Jensen MD, Kanaley JA, Reed JE, Sheedy PF. Measurement of abdominal and visceral fat with computed tomography and dual-energy x-ray absorptiometry. Am J Clin Nutr. 1995; 61:274-8.

36. Kweon S, Kim Y, Jang MJ, Kim Y, Kim K, Choi S, Chun C, Khang YH, Oh K. Data resource profile: the Korea National Health and Nutrition Examination Survey (KNHANES). Int J Epidemiol. 2014; 43:69-77. https://doi.org/10.1093/ije/dyt228.
37. Neuhouser ML, Lilley S, Lund A, Johnson DB. Development and validation of a beverage and snack questionnaire for use in evaluation of school nutrition policies. J Am Diet Assoc. 2009; 109:1587-92. https://doi. org/10.1016/j.jada.2009.06.365.

38. McLean RM. Measuring population sodium intake: a review of methods. Nutrients. 2014; 6:4651-62. https://doi. org/10.3390/nu6114651.

39. Stamler J. The INTERSALT Study: background, methods, findings, and implications. Am J Clin Nutr. 1997; 65:626S-42S. 